\title{
Corrigendum \\ Memories of Opiate Withdrawal Emotional States Correlate with Specific Gamma Oscillations in the Nucleus Accumbens
}

Cyril Dejean, Mathieu Sitko, Paul Girardeau, Amine Bennabi, Stéphanie Caillé, Martine Cador, Thomas Boraud and Catherine Le Moine

Neuropsychopharmacology (2017) 42, 1558. doi:10.1038/npp.2017.46

Correction to: Neuropsychopharmacology advance online publication, 4 January 2017; doi:10.1038/npp.2016.272
This article was originally published under SN's License to Publish, but has now been made available under a [CC BY 4.0] license. The PDF and HTML versions of the paper have been modified accordingly. 